\title{
CONSIDERAÇÕES SOBRE PERDAS GEOQUÍMICAS EM NASCENTES E SISTEMAS FLUVIAIS DE CABECEIRAS DE DRENAGEM NA BORDA OESTE DO ESPINHAÇO MERIDIONAL (MINAS GERAIS)
}

\author{
Luísa Lima Borges Ferreira $^{(\mathrm{a})}$, Antonio Pereira Magalhães Júnior ${ }^{(\mathrm{b})}$, Miguel Fernandes Felippe ${ }^{(\mathrm{c})}$, \\ Fernando César da Costa ${ }^{(\mathrm{d})}$
}

(a) Curso de Geografia /Instituto de Geociências, UFMG, luisalbferreira06@gmail.com

(b) Departamento de Geografia /Instituto de Geociências, UFMG, magalhaesufmg @ yahoo.com.br

(c) Departamento de Geociências / Instituto de Ciências Humanas, UFJF, miguel.felippe@ufjf.edu.br

(d) Laboratório de Geomorfologia / Instituto de Geociências, UFMG, labgeomorfo@igc.ufmg.br

\section{Eixo: SISTEMAS GEOMORFOLÓGICOS: ESTRUTURA, DINÂMICAS E PROCESSOS}

\begin{abstract}
Resumo
Este artigo busca apresentar e discutir os resultados de perdas geoquímicas em nascentes e sistemas fluviais de cabeceiras de drenagem em duas microbacias da Serra do Cipó, denominação regional do Espinhaço Meridional. Foram coletadas amostras de água em campanhas de campo trimestrais entre novembro de 2015 e setembro de 2016. Em laboratório, foram analisados os parâmetros TDS (Sólidos Totais Dissolvidos), sílica, alcalinidade e condutividade elétrica. Os resultados ilustram a realidade geoquímica das águas da Serra do Cipó. Os valores muito baixos dos elementos analisados corroboram a resistência dos materiais aos processos de intemperismo químico. Nuances podem estar relacionadas a características pedológicas, geológicas, vegetacionais e morfológicas muito específicas.
\end{abstract}

Palavras- chave: Desnudação geoquímica; Nascentes; Serra do Espinhaço; Evolução do relevo.

\section{Introdução}

O papel das nascentes e de cursos d'água de ordem inferior na perda de massa continental é ainda bastante pouco estudado e conhecido na literatura, em grande parte devido a expressarem a parcela subterrânea (não visível) da atuação dos processos de desnudação. No Brasil, os estudos também se concentram nas perdas geoquímicas derivadas de fluxos superficiais (SALGADO; VALADÃO, 2003; SALGADO et al., 2004; SARDINHA et al., 2012). As pesquisas sobre o tema envolvendo nascentes são ainda pouco frequentes (MAGALHÃES JR; FELIPPE, 2012; FELIPPE, 2013).

Este trabalho visa contribuir para as discussões sobre o significado das nascentes e canais de ordens inferiores na desnudação geoquímica e na evolução do relevo, especificamente na borda oeste da Serra do Espinhaço, estado de Minas Gerais. Este é um dos mais imponentes domínios geológicos e geomorfológicos do país, estendendo-se da borda norte do Quadrilátero Ferrífero, a sul, até o norte do estado da Bahia. A Serra é um grande divisor hidrográfico entre as importantes bacias dos rios São 


\section{OS DESAFIOS DA GEOGRAFIA FÍSICA NA FRONTEIRA DO CONHECIMENTO \\ Instituto de Geociências - Unicamp \\ Campinas - SP \\ 28 de Junho à 02 de Julho de 2017}

Francisco, Doce e Jequitinhonha, cuja dinâmica temporal conjunta e diferencial contribui decisivamente para o modelado regional. A análise das perdas geoquímicas na área dá continuidade a estudos anteriores de Felippe e Magalhães Jr (2016) no sentido de contribuir para a compreensão integrada dos processos que explicam a configuração e a evolução do Espinhaço. O objetivo principal do artigo é apresentar e discutir, comparativamente, os resultados de perdas geoquímicas em nascentes e sistemas fluviais de cabeceiras de drenagem em duas microbacias da Serra do Cipó, denominação regional do Espinhaço Meridional, a nordeste de Belo Horizonte.

\section{2.Área de estudos}

As duas microbacias estudadas situam-se na borda oeste da Serra do Cipó, uma subunidade da porção sul da Serra do Espinhaço situada a cerca de 100 km de Belo Horizonte (Figura 1).

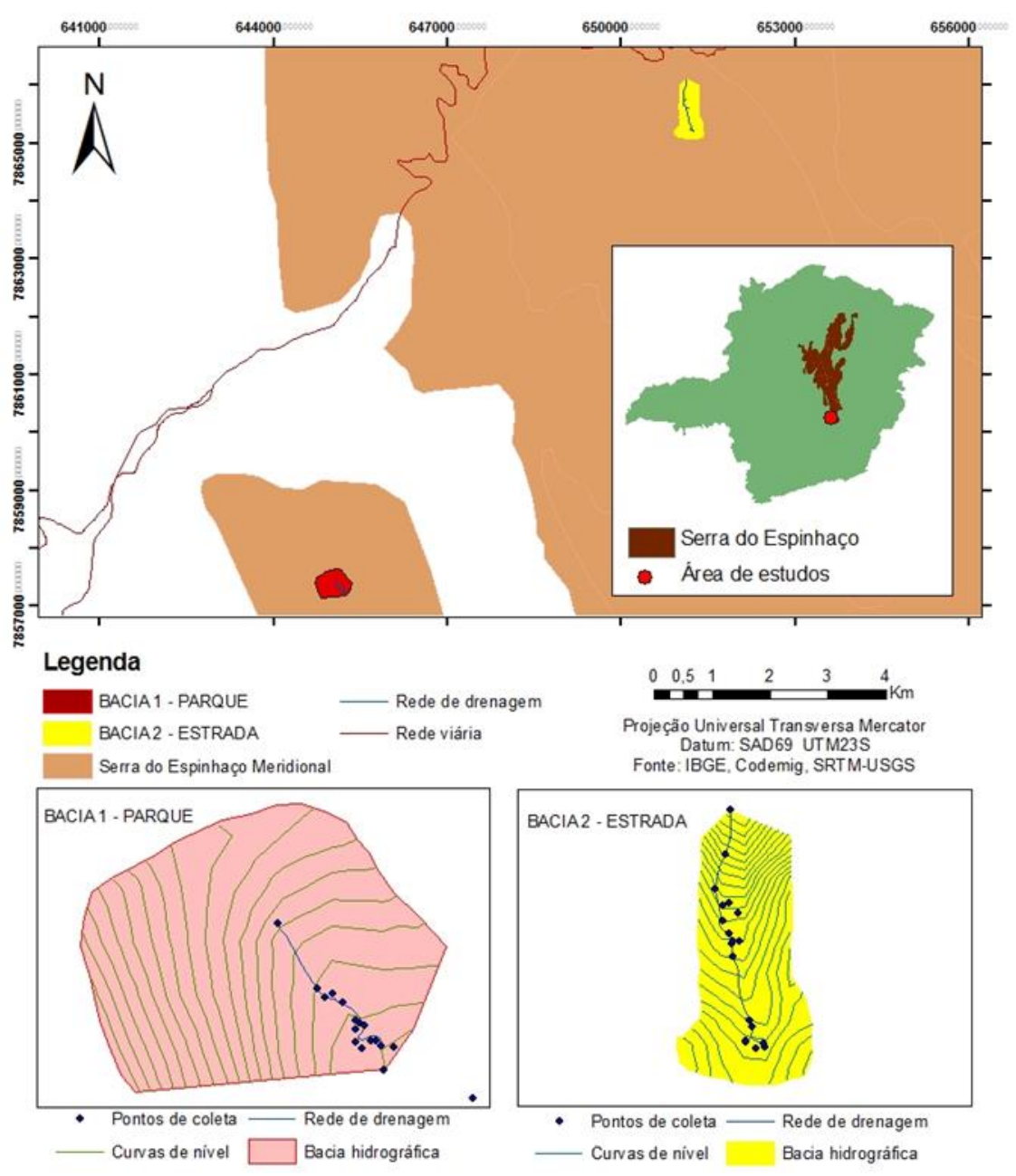

Figura 1 - Mapa de localização 
A Serra do Espinhaço se estrutura como uma faixa dobrada sustentada principalmente por um espesso pacote metassedimentar do Supergrupo Espinhaço (SAADI, 1995). Como unidade morfológica cimeira, regionalmente, atua como divisor entre as bacias dos rios São Francisco (oeste) e Doce (leste). A mencionada borda oeste marca a zona de contato entre o Espinhaço e a Depressão do AltoMédio São Francisco (IBGE, 2006), formada em grande parte por rochas do Grupo Bambuí, modelada em rochas sedimentares neoproterozoicas metamorfisadas durante os processos de (de)formação da cadeia do Espinhaço, com aumento progressivo da influência tectônica (dobras) para leste (ULHEIN et al., 1995). Neste sentido, a borda oeste da Serra do Espinhaço se configura em uma zona deformada pelos movimentos de empurrão da macroestrutura do Espinhaço sobre as rochas do Grupo Bambuí, consequentemente dobradas.

Esta faixa de contato geológico e geomorfológico é modelada principalmente em rochas metassedimentares glaciogênicas neoproterozóicas do Grupo Macaúbas, no qual se inserem as bacias estudadas, com destaque para metadiamictitos, quartzitos e metassiltitos (ALMEIDA-ABREU; RENGER, 2002). Estas rochas estão em contato com as do Grupo Conselheiro Mata, no topo da sequência do Supergrupo Espinhaço. Este Grupo é formado por um pacote de rochas oriundas de depósitos marinhos rasos (CHEMALE JR et al., 2011). A unidade litológica com maior representatividade espacial na Serra do Espinhaço é a Formação Galho do Miguel, em contato com o Grupo Conselheiro Mata, sendo formada essencialmente por espessos pacotes de quartzitos de origem eólica que podem atingir $3000 \mathrm{~m}$ de profundidade (ALMEIDA-ABREU, 1995). Devido à sua resistência aos processos de meteorização, estes quartzitos sustentam as cristas e superfícies cimeiras da Serra do Cipó (SALGADO; VALADÃO, 2003). A diversidade geológica regional resulta em um rico e complexo quadro hidrogeológico que condiciona os processos de desnudação geoquímica e as características das águas subterrâneas e superficiais.

A Serra do Cipó configura-se como um maciço planáltico orientado genericamente no sentido NWSE, com morfologia de cristas entrecortadas por vales fluviais com elevado grau de dissecação (FELIPPE; MAGALHÃES JR, 2016). A morfologia dissecada e os vales encaixados estão, muitas vezes, associados a escarpas de falha que coincidem com as principais frentes de cavalgamento identificadas por Almeida-Abreu (1995). Por sua vez, as bordas do planalto apresentam trechos com escarpas erosivas modeladas a partir da resistência litológica diferencial.

Ambas as microbacias situam-se em áreas com abundância de afloramentos rochosos e formações superficiais rasas e arenosas. Entretanto, há porções localizadas de solos profundos, principalmente na microbacia 1. A relação entre a litologia e as coberturas pedológicas é muito forte (FELIPPE, 2013). Predominam Neossolos Litólicos, Neossolos Quartzarênicos e Espodossolos nas áreas de quarzitos e metadiamictitos, e Cambissolos nas áreas recobertas por rochas carbonáticas. 
Em termos vegetacionais, a Serra do Cipó apresenta predomínio de campos rupestres e cerrado (IEF, 2009). Conforme o IBGE (2002) o clima local é sub-quente semiúmido, com temperaturas médias entre 15 e $18^{\circ} \mathrm{C}$ e 4 a 5 meses secos. A média de precipitação anual é de $1500 \mathrm{~mm}$, apresentando um período de excedente hídrico entre novembro a março, e um déficit entre abril e setembro. Há, portanto, um claro quadro de estacionalidade climática.

O Rio Cipó, formado pelo encontro do Rio Bocaína (direção E-W) e Rio Mascates (S-N) é o principal curso d'água que drena a Serra do Cipó. O Rio Cipó corre paralelo a Serra no eixo sul-norte até desaguar no Rio das Velhas, um dos principais afluentes do Rio São Francisco. A rede hidrográfica apresenta forte condicionamento estrutural, com frequentes segmentos retilíneos e bruscas mudanças de direção que refletem os lineamentos do substrato rochoso deformado. A microbacia 1 apresenta área de $232.317 \mathrm{~m}^{2}$ e está inserida no Parque Nacional da Serra do Cipó. É parte integrante da Bacia do Córrego do Capão, afluente do Rio Mascates. A Microbacia 2, possui área de $387.341 \mathrm{~m}^{2}$ e situa-se próxima ao trecho da MG010 que passa pelo distrito de Serra do Cipó. Apresenta um curso d'água principal sem denominação oficial, o qual deságua na margem direita do Rio Cipó à jusante do referido distrito.

A microbacia 1 ocorre em uma cabeceira de drenagem relativamente circular e assimétrica, com interflúvio nas cristas quartzíticas do Grupo Macaúbas. A drenagem converge para um único canal proeminente conectado a pequenos canais secundários de incisão incipiente a baixa. Os solos bem drenados e arenosos são intervalados por manchas de materiais mais argilosos e com maior concentração de matéria orgânica, sobretudo associados a maior proximidade do nível freático, formando pequenas e suaves depressões onde, muitas vezes, ocorrem nascentes. Com isso, os canais de primeira ordem formados possuem segmentos efêmeros e intermitentes bem caracterizados e que variam com a sazonalidade do nível freático.

Por sua vez, a microbacia 2 ocorre em um dos patamares mais elevados da Serra do Cipó, já caracterizada pelos quartzitos Galho do Miguel. Possui formato alongado com vertentes mais retilíneas se comparadas as da microbacia 1 . O canal principal é relativamente extenso se comparado aos secundários, determinando o direcionamento e alinhamento da microbacia. Com vastos afloramentos de quartzito, na bacia predominam solos rasos e extremamente arenosos; porém, em sua porção superior, há uma mancha de solos avermelhados mais profundos, onde ocorre a confluência das duas nascentes mais elevadas. A escala dos mapeamentos geológicos não permite afirmar, porém, acredita-se que essa configuração está relacionada a uma intrusão de rochas básicas, muito comum nesse contexto. 


\section{OS DESAFIOS DA GEOGRAFIA FÍSICA NA FRONTEIRA DO CONHECIMENTO \\ Instituto de Geociências - Unicamp \\ Campinas - SP \\ 28 de Junho à 02 de Julho de 2017}

\section{Materiais e métodos}

O trabalho foi realizado com base em trabalhos de campo para levantamentos in loco e coleta de amostras d'água. As campanhas de campo envolveram a mensuração de Sólidos Totais Dissolvidos (TDS) e dos parâmetros auxiliares sílica, alcalinidade e condutividade. A seleção dos parâmetros foi realizada buscando-se respeitar as características hidrogeológicas locais, assim como as recomendações de Feitosa e Manoel-Filho (1997), Hindi et al. (2003) e Salgado e Valadão (2003) para estudos de perdas geoquímicas.

Os pontos de coleta das amostras de águas foram pré-determinados segundo a hierarquia fluvial, contemplando nascentes (ordem 0) e canais de primeira e segunda ordem em duas microbacias: uma no interior do Parque Nacional da Serra do Cipó (microbacia 1; Figura 2) e outra próxima ao trecho da MG010 que passa pelo município de Santana do Riacho (microbacia 2; Figura 3). A escolha obedeceu à verificação da possibilidade de reconstituição da rede de drenagem em campo, com identificação das nascentes e das confluências que confirmassem a configuração de bacias de $2^{\mathrm{a}}$ ordem. Deste modo, ficou confirmada a possibilidade de acesso para coletas de água nas nascentes e nos cursos d'água.

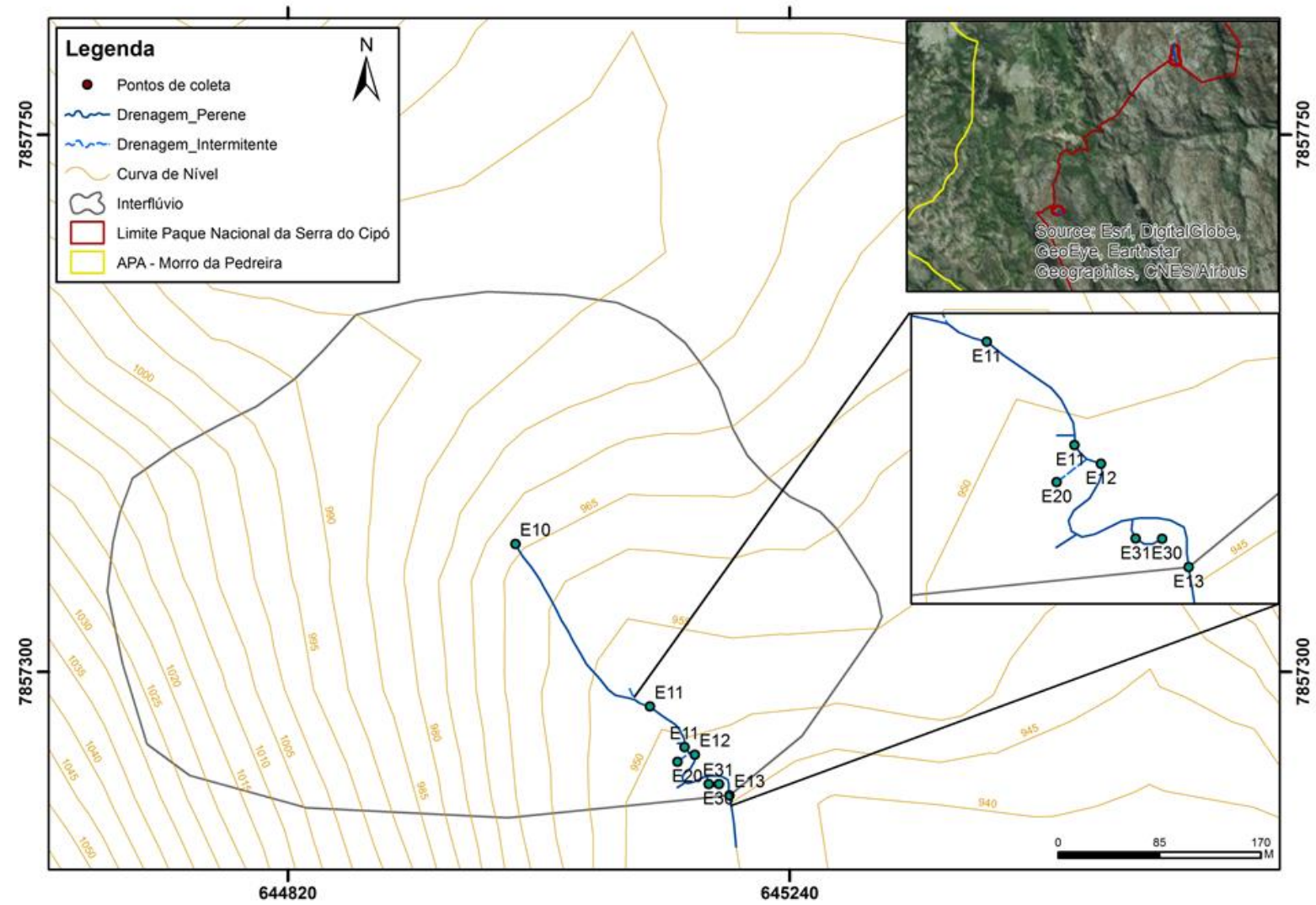

Figura 2 - Microbacia 1 - Parque Nacional da Serra do Cipó 


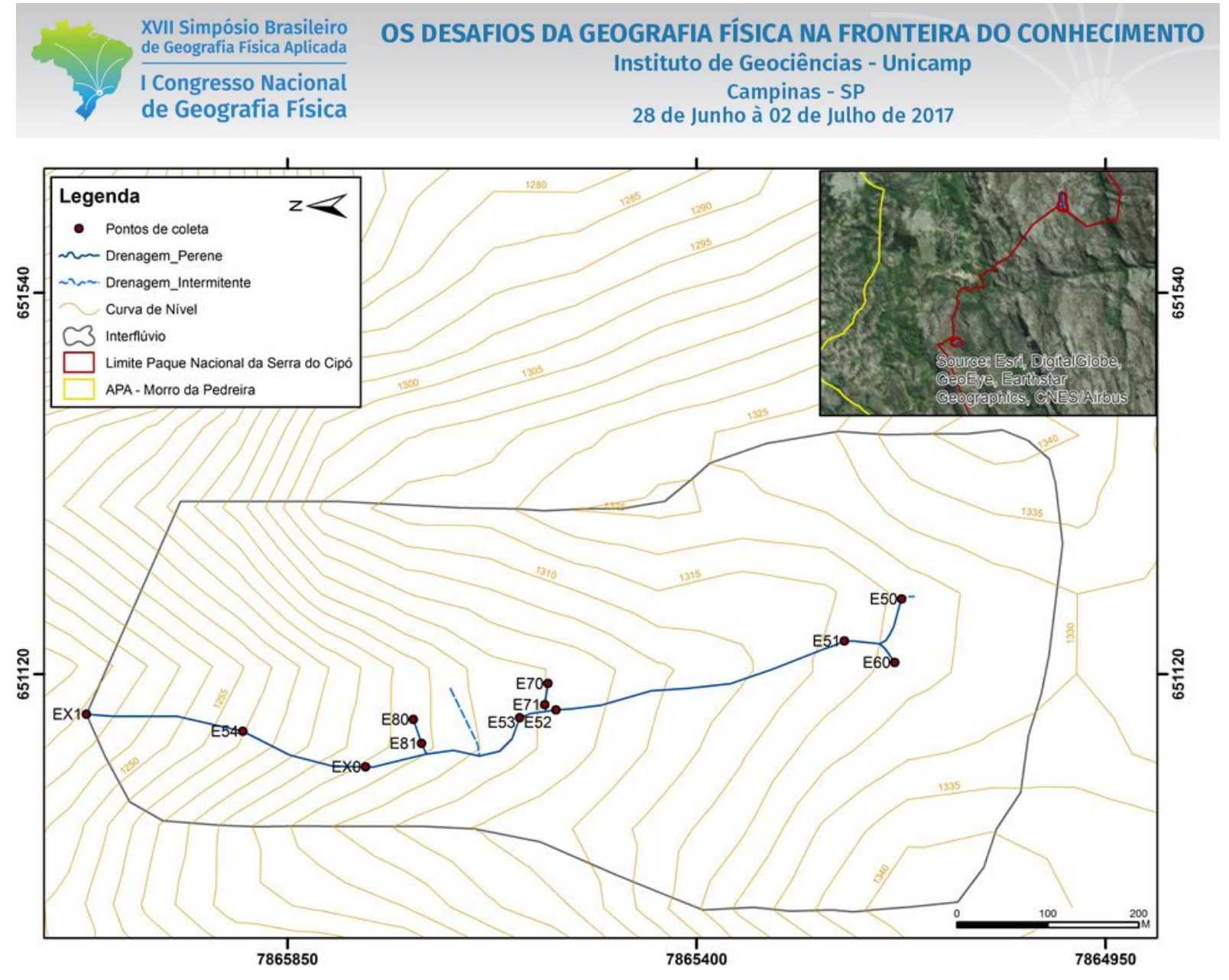

Figura 3 - Microbacia 2

Ao contrário da componente física da desnudação, em que há importantes dificuldades metodológicas de monitoramento e avaliação, as perdas geoquímicas podem ser mais facilmente mensuradas a partir das concentrações minerais em amostras de água. Por isto, os estudos geomorfológicos sobre o tema em meio tropical têm se concentrado nesta abordagem.

As amostras foram analisadas no Laboratório de Geomorfologia da UFMG (Universidade Federal de Minas Gerais), seguindo criteriosamente as normas do Standard Methods for Examination of Water and Wastewater (APHA; AWWA; WEF, 2012). Posteriormente, foi realizada a análise estatística, organização e tabulação dos dados, produção de gráficos e interpretação. Quatro trabalhos de campo, com intervalos trimestrais, foram realizados em novembro de 2015, março, junho e setembro de 2016, configurando um ano hidrológico e abarcando as estações úmida e seca.

A obtenção dos TDS foi realizada pela técnica da Gravimetria com as amostras filtradas, a partir da diferença de massa antes e após evaporação em estufa a $180^{\circ} \mathrm{C}$ durante 24 horas (ou até a secagem completa da capsula), com alíquotas de $100 \mathrm{~mL}$. As análises de alcalinidade foram realizadas em duplicatas. 


\section{OS DESAFIOS DA GEOGRAFIA FÍSICA NA FRONTEIRA DO CONHECIMENTO Instituto de Geociências - Unicamp \\ Campinas - SP \\ 28 de Junho à 02 de Julho de 2017}

A Sílica é determinada pela técnica de espectrofotometria na região do visível. O produto formado pela reação da Sílica com o Molibdato de Amônio em $\mathrm{pH}=1,2$ forma um complexo de coloração amarelada que é lida em $410 \mathrm{~nm}$. A intensidade da cor é proporcional à concentração do composto na amostra (APHA; AWWA; WEF, 2012). O cálculo da concentração é feito por meio da equação da reta obtida na curva de calibração. Foram preparados cinco padrões de $\mathrm{SiO} 2$ com concentrações de 2, 5, 10, 20 e $30 \mathrm{mg} / \mathrm{L}$ e realizadas as leituras em espectrofotômetro TECNAL V-5000, a $410 \mathrm{~nm}$. Os dados da leitura em absorvância x concentração do padrão em $\mathrm{mg} / \mathrm{L}$ foram plotados num gráfico obtendo-se uma reta $(\mathrm{r}=0,9969)$ e a equação de $1^{\circ}$ grau.

A alcalinidade foi obtida a partir da amostra filtrada (filtros de $0,45 \mu \mathrm{m}$ ) por titulação potenciométrica em titulador automático HANNA H1902 utilizando como titulante o HCL 0,1 M padronizado. A condutividade foi mensurada em laboratório a partir da amostra não filtrada utilizando-se um condutivímetro MS TECNOPOM mCa-150. A célula de condutividade com constante $\mathrm{k}=0,1$ é adequada para medida de soluções pouco concentradas aplicando-se precisamente na determinação desse parâmetro nas amostras coletadas em campo. As amostras foram armazenadas sob refrigeração em recipientes plásticos de $200 \mathrm{~mL}$, sem acidificação.

A análise e interpretação dos resultados laboratoriais foram realizadas por ponto amostral, situação no ano hidrológico e hierarquia fluvial. Também contou com a análise das médias por teste a cada campanha de campo, desconsiderando-se outliers e buscando visualizar a oscilação global dos dados. A tabulação e organização dos dados foram realizadas com o auxílio do software Excel, assim como a produção de gráficos como ferramenta para análise e interpretação dos dados.

\section{Resultados e Discussão}

Os resultados laboratoriais das bacias em estudo na Serra do Cipó (doravante denominadas microbacia 1 e microbacia 2) revelam certas tendências que contribuem para a análise da mineralização das águas e da desnudação geoquímica dos maciços rochosos da área. Os valores de TDS, e dos parâmetros auxiliares sílica, alcalinidade e condutividade elétrica, variaram de modo distinto ao longo do ano hidrológico analisado (Tabela I).

Tabela I- Resultados dos parâmetros geoquímicos por ponto de monitoramento

\begin{tabular}{|c|c|c|c|c|c|c|c|c|c|c|c|c|c|c|c|c|c|}
\hline \multirow{2}{*}{$\begin{array}{c}\text { Amos } \\
\text { tra }^{1}\end{array}$} & \multicolumn{1}{|c|}{ TDS GRAVIMÉTRICO (mg/L) } & \multicolumn{1}{|c|}{ ALCALINIDADE $(\mathbf{m g} / \mathbf{L})$} & \multicolumn{1}{c|}{ CONDUTIVIDADE $(\boldsymbol{\mu} / \mathbf{c m})$} & \multicolumn{4}{|c|}{ SÍLICA (mg/L) } \\
\hline E10 & NOV & MAR & JUN & SET & NOV & MAR & JUN & SET & NOV & MAR & JUN & SET & NOV & MAR & JUN & SET \\
\hline E11 & 0 & 6 & 24 & 76 & 3,5 & 4,5 & 3,0 & 4,0 & 3,59 & 7,35 & 3,95 & 8,34 & & & 1,51 & 7,96 \\
\hline E12 & -2 & 12 & 8 & 67 & - & 5,0 & 3,5 & 4,0 & - & 3,55 & $2,74 *$ & 6,62 & & & 2,42 & 6,9 \\
\hline E20 & 30 & - & 16 & 62 & 5,5 & 3,5 & 2,5 & 3,0 & 5,29 & - & 6,66 & 6,80 & & & 1,50 & 7,92 \\
\hline E21 & - & - & - & - & - & - & - & - & - & - & - & - & & & - & - \\
\hline E22 & 10 & - & - & - & 11,5 & - & - & - & 6,01 & - & - & - & & & - & - \\
\hline E30 & 20 & - & 8 & 38 & 6,5 & - & 3,0 & 3,0 & 6,74 & - & 6,86 & 6,64 & & & 4,25 & 9,34 \\
\hline E31 & 0 & - & 26 & 78 & 5,0 & - & 3,0 & 3,0 & 4,35 & - & 4,97 & 6,58 & & & 1,96 & 9,34 \\
\hline
\end{tabular}




XVII Simpósio Brasileiro
OS DESAFIOS DA GEOGRAFIA FISICA NA FRONTEIRA DO CONHECIMENTO
In Geografia Fisica Aplicada
I Congresso Nacional
de Geografia Física

Observações: ${ }^{1}$ Os algarismos finais das amostras representam a hierarquia fluvial, ou seja: 0 - nascentes; 1 curso d'água de ordem $1 ; 2$ - curso d'água de ordem $2 ;{ }^{3}$ - os dados de sílica só foram medidos em junho e setembro. ${ }^{2}$ Os campos marcados com “_“ representam ausência de fluxos no período em questão (ponto seco).

Em termos gerais, os valores de TDS foram marcadamente mais elevados em setembro de 2016, principalmente na microbacia 1. Esse período, marca o fim da estação seca e, por isso, a menor taxa de mistura (água subterrânea/água meteórica) nas nascentes e o maior tempo de residência médio para as águas exfiltradas. Desse modo, com mais tempo de atuação dos processos químicos e menor diluição pelas chuvas, a tendência é de valores de TDS mais altos. Também devido a representar o final da estação seca, muitos pontos não apresentaram fluxos em setembro, principalmente na microbacia 2. A única nascente perene ao longo dos 4 períodos de monitoramento foi a E10 (microbacia 1).

Na microbacia 1, houve casos de redução dos valores entre março e junho (E10, E12), mas também de aumento (E11). Já em setembro, todos os pontos com fluxos ativos apresentaram aumento significativo, refletindo os efeitos de toda a estação seca. O aumento chegou a 737 \% no ponto E12. Nas nascentes, a elevação foi de 216 \% na E10, 287 \% na E20, e 375 \% na E30. Na microbacia 2, a elevada frequência de pontos sem fluxos prejudica a avaliação. Porém, pode-se identificar uma tendência geral de aumento das concentrações entre março e setembro nos pontos ativos. Excetuandose os casos abaixo dos limites de deteç̧ão, os valores variaram entre 3 e $78 \mathrm{mg} / 1$ nas duas microbacias, ao longo dos 4 períodos.

Apesar da variação no comportamento dos valores de TDS em função da hierarquia fluvial, não houve tendências muito marcantes. Em certos casos, os valores das nascentes são superiores aos dos canais de $1^{\mathrm{a}}$ e $2^{\mathrm{a}}$ ordens, mas em outros verifica-se o contrário. As nascentes tendem a traduzir de forma mais fidedigna as características das águas subterrâneas, possuindo, em tese, menor influência dos processos meteóricos e superficiais. A nascente E10, na microbacia 1, ilustra bem esta tendência. Os seus valores foram superiores aos do canal de $1^{\text {a }}$ ordem (E11) em março, junho e setembro (em novembro de 2015 não havia exfiltração). Em março e em setembro, também há aumento de TDS 
entre o E11 e o E12, não verificando-se a tendência de redução do TDS com o aumento da vazão. Este fato pode derivar de perdas geoquímicas realizadas nas coberturas superficiais presentes entre os canais de $1^{\mathrm{a}}$ e $2^{\mathrm{a}}$ ordem.

Estes processos de mineralização das águas superficiais também devem ocorrer no segmento fluvial entre a nascente E30 e o ponto E31 ( $1^{\mathrm{a}}$ ordem). Neste caso, os dados de TDS da E30 foram $69 \%$ e 51 $\%$ inferiores aos do ponto E31. Portanto, na mesma microbacia 1, parece haver trechos da drenagem submetidos ao enriquecimento mineral superficial e outros não.

Já na microbacia 2 foi verificada uma tendência distinta. Entre março e junho os valores de TDS apresentaram uma elevação importante, em termos gerais. Nas duas nascentes ativas em junho, o aumento foi de $245,5 \%$ na E50 e de $150 \%$ na E80.

Ao longo da drenagem os valores se mantiveram relativamente próximos em março, mas houve uma importante redução do TDS da nascente E10 para o ponto E11 (-416 \%), e uma significativa elevação do ponto E11 para o E12 (+100 \%). Novamente percebe-se um enriquecimento mineral superficial ao longo da rede de drenagem. Em setembro, os valores aumentaram pouco na nascente E50 em relação a junho (5,2 \%), mas bastante no ponto E51 (211,1\%). Estes foram os únicos pontos com fluxos ativos na microbacia 2, neste mês. Excetuando-se os casos abaixo dos limites de detecção, os valores situaram-se entre 18 e $70 \mathrm{mg} / \mathrm{l}$, ou seja, superiores, em termos gerais, aos da microbacia 1.

Os maiores valores dos dados em setembro refletem a importante sazonalidade do clima regional. Esta constatação difere dos resultados de TDS encontrados por Felippe e Magalhães Jr (2016) em nascentes da mesma área. Os autores verificaram pequena variação dos dados entre os períodos seco e úmido, com valores sempre inferiores a $50 \mathrm{mg} / \mathrm{L}$. Este limiar foi ultrapassado em setembro na nascente E10 (76 mg/L), situada na microbacia 1. No geral, os dados de TDS também foram superiores aos encontrados na Serra do Espinhaço por Leão et al. (2012), para canais de ordens superiores.

Trabalhos anteriores na Serra do Espinhaço encontraram valores de sílica que oscilam entre 2 e 10 mg/L (SALGADO; VALADÃO, 2003; FELIPPE, 2013; FELIPPE; MAGALHÃES JR, 2016). Geralmente, os baixos valores de sílica refletem a sua baixa solubilidade natural. Esta tendência se manteve nos resultados deste trabalho, mas com diversos pontos apresentando valores abaixo de 2 $\mathrm{mg} / \mathrm{L}$ em novembro, março e junho. Por outro lado, os 9 pontos com fluxos ativos em setembro apresentaram valores bastante superiores, entre 6,91 e 9,34 mg/L.

Deste modo, houve tendência de forte oscilação dos valores em função da sazonalidade, assim como verificado para o TDS (Tabela 1). Na microbacia 1 o significativo aumento entre junho e setembro atingiu $427 \%$ na nascente E10, $218 \%$ no E11, $185 \%$ no E12, $424 \%$ e $119 \%$ nas nascentes E20 e E30, respectivamente, e $374 \%$ no E31. Na microbacia 2, os percentuais de aumento foram bem maiores nos dois pontos com fluxos ativos: $5729 \%$ na nascente E50 e $8380 \%$ no ponto E51. 
A sílica é a principal componente do parâmetro TDS nas águas das nascentes situadas no Grupo Macaúbas da borda oeste da Serra do Cipó (Felippe e Magalhães, 2016). Nos quartzitos os carbonatos, metais alcalinos e a sílica amorfa são praticamente inexistentes, ocorrendo, entretanto, óxidos e a própria sílica na forma de quartzo. Por esse motivo o esvaziamento geoquímico dos quartzitos Macaúbas é bem mais lento do que em litologias adjacentes como as rochas carbonáticas do Grupo Bambuí.

Em relação aos dados de alcalinidade houve uma tendência de queda dos valores entre março e junho em todos os pontos com exfiltração ativa na microbacia 1, passando a uma elevação generalizada em setembro. Já na microbacia 2 não houve reduções de valores em junho e setembro, mas somente manutenção ou elevação. Os dados variaram ligeiramente, situando-se, em grande parte, entre 3,0 e $5,0 \mathrm{mg} / \mathrm{L}$ de $\mathrm{CaCO}_{3}$ (Tabela 1). Estes valores são considerados muito baixos em comparação com os encontrados na literatura. As nascentes apresentaram valores sempre inferiores ou iguais aos dos pontos situados nos cursos d'água.

Os dados de condutividade elétrica são complementares aos demais, auxiliando as interpretações à luz de suas relações com o TDS (Tabela 1). Na microbacia 1, os dados de novembro e junho foram superiores nos canais de primeira ordem em relação à nascente, enquanto que em março e setembro foram inferiores. Na microbacia 2, os valores decrescem com o aumento da hierarquia fluvial em março e junho, e aumentam em novembro e setembro. Há pontos com maiores valores em novembro (E11), março (E11, E51, E52, E53), junho (E13, E30, E50 e E80), bem como em setembro (E10, E12, E31). Cabe destacar o valor de 14,01 microS/cm encontrado no ponto E80 da microbacia 2, bem mais elevado do que os demais obtidos.

Em termos de crescimento percentual, destaca-se a nascente E10 com elevação de 111,1 \% em setembro, em relação a junho. Porém, enquanto o ponto no canal de $1^{\text {a }}$ ordem (E11) apresenta queda de $3,5 \%$ da alcalinidade em setembro, no canal de $2^{\mathrm{a}}$ ordem (E12) verifica-se um crescimento ainda maior do que na nascente: 141,6\%. Estes dados coincidem com o comportamento do TDS na sequência E10-E11-E12, reforçando a hipótese de lixiviação de coberturas intemperizadas pelos fluxos superficiais. Esta hipótese também pode explicar dois outros casos: redução dos valores das nascentes E30 e E50 em setembro (3,2 \% e $51 \%$, respectivamente), enquanto os pontos à jusante, E31 e E51, apresentaram, ambos, elevação de $32,4 \%$. Novamente parece haver a indicação de que o final do período seco (setembro), em que os fluxos de base tem uma participação quase total na exfiltração, tende a apresentar uma mineralização superficial importante em curtos segmentos fluviais.

Valendo-se da relação entre os testes de condutividade elétrica e sólidos totais dissolvidos (TDS), o comportamento dos dados foi mais coerente, em termos esperados, em março e setembro, para a microbacia 1, e março e junho, para a microbacia 2. 


\section{Considerações Finais}

Em ambientes tropicais a análise geoquímica das águas apresenta-se como uma alternativa importante para o estudo da evolução do modelado. Durante os 4 períodos de monitoramento houve uma tendência importante de influência da sazonalidade, com mudanças significativas em setembro, com relação a junho.

A hierarquia fluvial parece ser um componente importante na compreensão da carga química das águas fluviais. Para o caso das cabeceiras estudadas na Serra do Cipó, há uma tendência de aumento do TDS com a diminuição da hierarquia. Por outro lado, os dois parâmetros químicos que constituem o TDS (considerados pela literatura como estando entre os mais significativos na mineralogia das águas desse contexto geológico) analisados nesse estudo, evidenciam o contrário. Isso leva a crer que a presença de ácidos orgânicos relacionados à decomposição da matéria orgânica em ambientes de hidromorfismo pode ser mais relevante do que se pensava anteriormente; o que explicaria nascentes com TDS mais elevado e sílica e alcalinidade mais baixas do que seus canais de maior hierarquia.

Apesar de diferenças encontradas entre as microbacias, ambas representam a realidade geoquímica das águas da Serra do Cipó (e do Espinhaço de um modo geral). Os valores muito baixos dos elementos analisados corroboram a resistência dos materiais aos processos de intemperismo químico. Nuances podem estar relacionadas a características pedológicas, geológicas, vegetacionais e morfológicas muito específicas e locais que somente estudos verticalizados permitiriam compreender.

\section{Agradecimentos}

Ao $\mathrm{CNPq}$ pelo apoio financeiro relativo ao projeto "O papel das nascentes e cabeceiras de drenagem na evolução de unidades do relevo de Minas Gerais por meio da análise dos processos de desnudação geoquímica". Ao Laboratório de Geomorfologia do IGC/UFMG e ao Grupo de Pesquisa Geomorfologia e Recursos Hídricos (CNPq).

\section{Referências bibliográficas}

ALMEIDA-ABREU, P. A. O supergrupo Espinhaço da Serra do Espinhaço meridional (Minas Gerais): o rifte, a bacia e o orógeno. Belo Horizonte: Geonomos, v. 3, n. 1, p. 1-18, 1995.

ALMEIDA-ABREU, P. A.; RENGER, F. E. Serra do Espinhaço meridional: um orógeno de colisão do mesoproterozóico. Revista Brasileira de Geociências, v. 32, n.1, p. 1-14, 2002.

APHA - AMERICAN PUBLIC HEALTH ASSOCIATION; AWWA - AMERICAN WATER WORKS ASSOCIATION; WEF - WATER ENVIRONMENT FEDERATION. Standard Methods for Examination of Water and Wastewater. Washington: APHA, 22 har., Cdr Edition, 2012.

CHEMALE JR, F.; DUSSIN, I. A.; MARTINS, M.; SANTOS, M. N. Nova abordagem tectono-estratigráfi ca do Supergrupo Espinhaço em sua porção meridional (MG). Belo Horizonte: Geonomos, v. 19, CPMTC-UFMG, p. 173-179, 2011. 
FEITOSA, A. C.; MANOEL-FILHO, J. (eds.). Hidrogeologia: conceitos e aplicações. Fortaleza: CPRM, 1997. $412 \mathrm{p}$.

FELIPPE, M. F. Gênese e dinâmica de nascentes: contribuições a partir da dinâmica hidrogeomorfológica em região tropical. 2013. Tese (Doutorado)... Belo Horizonte: Universidade Federal de Minas Gerais, 2013. 185 p.

FELIPPE, M. MAGALHÃES Jr, A P. A contribuição das nascentes na desnudação geoquímica: Borda oeste da Serra do Espinhaço Meridional (Minas Gerais, Brasil). Brasília: Revista Brasileira de Geomorfologia, v17, n.1, p. 79-92, 2016.

HINDI, E.; ROSA-FILHO, E.; BITTENCOURT, A.; XAVIER, J., Características hidrogeológicas do aqüífero costeiro da Ilha dos Valadares, PR (Brasil) e sua utilização para abastecimento público. Revista LatinoAmericana de Hidrogeologia, n.3, p. 19-31, 2003.

IBGE - INSTITUTO BRASILEIRO DE GEOGRAFIA E ESTATÍSTICA. Rio de Janeiro: Mapa de climas do Brasil. Escala 1:5.000.000. IBGE, 2002.

IBGE - INSTITUTO BRASILEIRO DE GEOGRAFIA E ESTATÍSTICA. Rio de Janeiro: Mapa de unidades de relevo do Brasil. Escala 1:5.000.000. IBGE, 2006.

IEF - INSTITUTO ESTADUAL DE FLORESTAS. Belo Horizonte: Mapa das coberturas vegetais do estado de Minas Gerais. Escala 1:1.000.000. IEF, 2009.

LEÃO, M. R.; REZENDE, E. A.; SALGADO, A. A.; NAILINI JR, H. A. Erosão, denudação e evolução do relevo da média Serra do Espinhaço meridional, Minas Gerais. Brasília: Revista Brasileira de Geomorfologia, v.13, n.2, p.113-124, 2012.

MAGALHÃES JR., A. P.; FELIPPE, M. F. The Importance Of River Springs In Sustainable Water Management: The City Of Belo Horizonte, Brazil. In: BILIBIO, C.; HENSEL, O.; SELBACH, J.F. (Org.). Sustainable water management in the tropics and subtropics - and case studies in Brazil. Jaguarão/RS: Unipampa; UNIKASSEL; PGCult-UFMA, 2012, v.3, p. 299-346.

SAADI, A. A geomorfologia da Serra do Espinhaço em Minas Gerais e de suas margens. Belo Horizonte: Geonomos, v. 3, n. 1, p. 41-63, 1995.

SALGADO, A. A.; VALADÃO, R. C. Contribuição da Desnudação Geoquímica na Evolução da Erosão Diferencial no Espinhaço Meridional - MG. Brasília: Revista Brasileira de Geomorfologia. Brasília: v. 4, № 2, p. 31-40, 2003.

SALGADO, A. A. R.; VARAJÃO, C. A. C.; COLIN, F.; BRAUCHER, R.; NALINI JUNIOR, H. A.; VARAJÃO, A. F. D. O papel da denudação geoquímica no processo de erosão diferencial no Quadrilátero Ferrífero/MG. Brasília: Revista Brasileira de Geomorfologia, v. 5,n. 1, p. 55-69, 2004.

SARDINHA, D. S.; BONOTTO, D. N.; GODOY, L. H.; CONCEIÇÃO, F. T.; MORENO, M.M. T., Denudação química e implicações na composição das águas superficiais da bacia do rio Jaú (SP). Brasília: Revista Brasileira de Geomorfologia, v.13, n.3, p.337-349, 2012..

ULHEIN, A.; TROMPETTE, R.; EGYDIO-SILVA, M. Rifteamentos superpostos e tectônica de inversão na borda sudeste do cráton do São Francisco. Belo Horizonte: Geonomos, v. 3, n. 1, p.99-107, 1995. 